\title{
Strategies for Managing the Impacts of Disruptions During COVID-19: an Example of Toilet Paper
}

\author{
Sanjoy Kumar Paul ${ }^{1}$ (D) Priyabrata Chowdhury ${ }^{2}$
}

Received: 14 May 2020/Accepted: 30 June 2020/Published online: 12 July 2020

(C) Global Institute of Flexible Systems Management 2020

\begin{abstract}
Due to the recent pandemic of coronavirus, known as the COVID-19 outbreak, the supply chains have been impacted most significantly. Manufacturers of certain items have experienced a substantial increase in demand, and on the other hand, raw materials supply, to produce those items, has reduced because of supply failure. To overcome these challenges, this paper proposes some strategies to improve service level during an extraordinary pandemic outbreak, such as COVID-19, for the most wanted products such as toilet paper. This study considers meeting the increased demand of the customers for an essential product of daily life like toilet paper during a pandemic is beyond the traditional economic objective, i.e., increase profit, of the manufacturers. Instead, this should be more about the social responsibility of all the manufactures to ensure that they can serve more customers. Motivated by this and taking toilet paper as an example of the product, we first analyzed the current scenario of the manufacturing and the demand for the product and then proposed some strategies to deal with this unprecedented risk and analyzed the results. We have compared the results, using hypothetical data, between the current scenario and proposed strategies. The result shows that sharing information and resources from all manufacturers to produce under a single brand, emergency sourcing,
\end{abstract}

Sanjoy Kumar Paul

Sanjoy.Paul@uts.edu.au

Priyabrata Chowdhury

priyabrata.chowdhury@rmit.edu.au

1 UTS Business School, University of Technology Sydney, Sydney, Australia

2 School of Accounting, Information Systems and Supply Chain, RMIT University, Melbourne, Australia producing basic quality items, and packing in the smallest sizes have a significant positive impact on the service level. This paper first investigates the strategies for a high-demand and essential item during a pandemic situation and proposes strategies to deal with this unique, extraordinary disruption.

Keywords COVID-19 · High-demand items · Pandemic . Strategies $\cdot$ Supply chain disruptions

\section{Introduction}

The coronavirus disease (COVID-19) outbreak, which was first reported in Wuhan, China, in December 2019, has affected 215 countries and territories with more than 9.5 million cases and more than 485 thousand deaths as of 25 June 2020 (Worldometers 2020). This outbreak has already affected almost all sectors and most of the countries across the globe (Dryhurst et al. 2020); therefore, the World Health Organization (WHO) has marked it as a pandemic on 11 March 2020. A pandemic is a unique case of supply chain disruptions that do have not only severe but also long-lasting impacts on the operations of a supply chain. Any epidemic outbreaks, which can be contained geographically, are generally perceived as disruptions that have high uncertainty (Paul et al. 2013; Paul et al. 2014a, b, c), long-term existence, and ripple effect (Ivanov 2020a). In recent years, firms have been experiencing more numbers of epidemic outbreaks. For example, the WHO reported 1438 epidemics between 2011 and 2018 with huge impacts such as loss of life and economic slowdown (Hudecheck et al. 2020). In the case of a pandemic, companies in various sectors experience different types of challenges. For example, while many companies in 
different sectors, such as fashions and athletics, are shutting down their operations worldwide, as predicted in Haren and Simchi-Levi (2020), demand for certain products spikes suddenly. Toilet paper is such of type of product, the demand of which has suddenly increased, and companies across the globe are struggling to meet the demand. As a result, companies are unable to cope up with this panic buying even after limiting the number of buying allowed per customer. In many countries, the toilet paper of all supplying companies is stock-out, and there is no other substitute product available in the market; hence, general customers become panic, as the product is essential for daily life. Hence, it is crucial to develop strategies for managing the demand of an essential item like toilet paper during a pandemic. However, the studies on strategies and their impact on the service level for a high-demand and essential item during a pandemic are nonexistent in the literature. Considering the lack of studies in the literature, this study establishes following research questions.

1. What are the strategies that can be used to manage the increased demand for an essential item during a pandemic like COVID-19?

2. How can managers evaluate the improvement in service level after implementing the strategies?

Traditional supply chain disruption preparedness, mitigating, and recovery strategies cannot be used for planning recovery from this situation as many of these strategies are simply not sufficient for this particular case of disruptions (Paul et al. 2017; Darom et al. 2018; Dryhurst et al. 2020; Ivanov 2020a). Instead, an adaptive strategy, which includes restructuring the supply chain, facing a supply chain disruption, and its impact are required (Paul et al. 2014a; Zhao et al. 2019; Islam et al. 2020). A recent study (Kahiluoto et al. 2020) has shown that a response diversity to disruptions is more effective than mere diversity, such as diversity to individual suppliers. Furthermore, Koonin (2020) suggests to update and modify the supply chain response strategies for a particular product when a significant disruption like COVID-19 occurs to ensure that firms can minimize the variation between demand and supply. In the current situation of COVID-19, we argue that with a response diversity, the demand spikes of toilet paper could be managed in a better way. Managing the demand of such an essential product of daily life is vital; otherwise, the regular activities of the mass people might be impacted. As such, addressing the pressing demand of individuals and communities through developing strategies and using unique assets and capabilities, for an essential product, is a social responsibility of the companies (Hills 2020). An adequate attempt to meet this increased demand can also improve other social responsibility practices such as the creation of more jobs for producing and distributing the products (Govindan et al. 2014; Chowdhury and Paul 2020).

Based on the limitations of the applicability of previous studies on strategies for managing impacts of COVID-19, for a high-demand and essential item, this study considers the following research objectives.

1. To identify appropriate strategies for a high-demand and essential item during a pandemic, like COVID-19.

2. To develop an analytical model for the service level to show the benefits of strategies for managing the impacts of COVID-19.

Therefore, this study contributes to the literature by developing an analytical model with several strategies that can improve the service level of manufacturers of essential items, thereby improving their social responsibility practices in such an extreme situation of supply shortage. The proposed strategies can be applied whenever there is a nation-wide shortage of the supply of essential products such as toilet papers.

In developing the analytical model to solve this nationwide supply shortage problem of toilet papers, we first focus on the current practices adopted by the firms to face this crisis. Then, we proposed, with appropriate justifications, several strategies that could be used in line with the current practices to solve the problem. Finally, using hypothetical data, we compare the service level in both the current situation and proposed strategies to justify the value of the proposed approaches. Finally, the implications of the study are discussed with a concluding remark.

\section{Literature Review}

In this section, we conduct a literature review on various types of supply chain risks and strategies for disruption risks. Based on the findings of the current literature, we identify the knowledge gaps to highlight the contributions of this study.

\section{Supply Chain Risk}

Risks in the context of the commercial supply chain are generally classified into two groups-operational risk and disruption risk. The former one denotes the risk events that can be predicted and are more controllable such as quality and quantity problem and longer lead time (Chowdhury et al. 2019; Saha et al. 2020). On the other hand, disruption risks refer to catastrophic events that are less controllable such as fire, machine breakdown, and natural disasters (Paul et al. 2016; Ray and Jenamani 2016; Lücker et al. 2019; Fartaj et al. 2020). Previous studies have indicated that different strategies are required to respond to these two 
categories of risks. For example, appropriate mitigation strategies to minimize the probability of occurring the incidents are suggested for operational risks (Chen et al. 2013; Paul et al. 2015b; Chowdhury et al. 2016). However, for disruption risks appropriate recovery plan and strategies to minimize the impacts of the risks and to back to the normal operations are considered more suitable (Paul et al. 2015a; Ivanov et al. 2017; Ivanov 2019; Paul et al. 2019a). This is only recently when scholars are suggesting to explore the third category of risks termed as extraordinary risks, which refer to epidemic or pandemic outbreaks, for commercial products.

While some features of such extraordinary risks are prevalent in disruption risks such as they both are unpredicted and uncontrollable, the third risk category is unique for its features (Cappelli and Cini 2020; Choi 2020; Ivanov and Dolgui 2020). For example, extraordinary outbreaks are characterized by a long-term existence of the risk impacts, high uncertainty of the future impacts, and the ripple effect of the event on other functions or processes (disruption propagation) (Ivanov 2020a). Moreover, while these extraordinary risk events have simultaneous impacts on sourcing, production, and demand management, the impacts are different for various types of products, such as high-demand and essential items, regular items, and fashion products (Paul and Chowdhury 2020). Due to its unique characteristics, an adaptive set of strategies is required to overcome such extraordinary risks for each type of product. However, current literature on epidemic or pandemic outbreaks in the contexts of commercial products is minimal and is unable to provide such adaptive strategies.

\section{Strategies for Supply Chain Disruption}

Strategies for managing supply chain disruptions in an extraordinary epidemic or pandemic outbreak are mostly investigated in the context of humanitarian supply chains (Dasaklis et al. 2012; Paul and Chowdhury 2020). Several strategies such as flexible orientation (Altay et al. 2018), on-time and speedy information sharing (Altay and Pal 2014; Scholten et al. 2014), implementation of the triple-A supply chain components-agility, adaptability, and alignment (Oloruntoba and Gray 2006; Dubey and Gunasekaran 2016), adaptive recovery plan, and employee support (Scholten et al. 2014) are found useful for recovering from epidemic outbreaks or severe disruptions in humanitarian supply chains. The role of leadership is also explored and confirmed in humanitarian supply chains as an appropriate leadership style assists quick recovery via improving cooperation with different stakeholders (Salem et al. 2019). However, humanitarian supply chains are significantly different from commercial and business supply chains (Oloruntoba and Gray 2006; Yadav and Barve
2016). As a result, the findings of humanitarian supply chains are not readily applicable to manage commercial supply chains.

Although not focused on extraordinary outbreaks, studies focusing on disruption risk have recommended various recovery strategies for commercial supply chains. Among them, relational strategies such as supply chain collaboration and information sharing are commonly suggested in previous studies (Chen et al. 2019; DuHadway et al. 2019). Both horizontal and vertical alliances contribute to quick recovery from a disruption risk (Chen et al. 2019). In this regard, collaborative planning with other supply chain partners is essential (Kumar and Anbanandam 2020). Studies also suggested supply chain information sharing and connectivity for disruption recovery (Dubey et al. 2018; Chang et al. 2019; Chen et al. 2019). These relational strategies help recover from disruptions by enhancing the triple-A supply chain performance. Moreover, the triple-A components are interconnected (Aslam et al. 2018; Wamba et al. 2020); hence, one component contributes to disruption recovery by influencing others. To improve relational infrastructure, the role of technology, internal and external process connectivity, and big data are also highlighted (Roscoe et al. 2020). A recent study investigated the production recovery plan for a high-demand item by considering the impacts of COVID-19 also finds that collaboration can help in quick recovery (Paul and Chowdhury 2020).

Another common disruption recovery strategy is flexibility in supply chains (Singh and Acharya 2013; PérezPérez et al. 2019). Studies reveal that an adaptive supply chain recovery strategy is required for each supply chain disruption risk. Therefore, adjusting tactics and operations for recovering from disruptions is essential (Paul et al. 2014b; Gligor et al. 2019; Paul et al. 2019b; Kumar and Anbanandam 2020). Moreover, a flexible supply chain network structure is found appropriate for formulating appropriate disruption risk recovery strategies (Dubey et al. 2015; Gunasekaran et al. 2016; Ivanov and Sokolov 2019). Indeed, such ability to redesign the supply chain network by considering medium-to-long-term impacts of a disruption risk is known as viability and is suggested as an effective recovery strategy for the current COVID-19 (Ivanov 2020b).

In addition to relational and flexible strategies, some other strategies also can be found in the literature. For example, buffer strategies such as backup and alternative suppliers (Al Masud et al. 2014; Paul et al. 2018; Chen et al. 2019), buffer inventory or material (Darom et al. 2018; Paul and Rahman 2018), capacity increase or utilizing reserved capacity (Paul et al. 2014a; Ivanov et al. 2016), and imposing compensation policy for keeping customers waiting (Shao and Dong 2012) are suggested for 
disruption recovery. Paul and Chowdhury (2020) recommend increasing production capacity via utilizing more shifts, hiring more staff and buying more machinery, and emergency sourcing for high-demand items to recover from the impacts of an extraordinary outbreak such as COVID-19.

\section{Knowledge Gaps}

As outlined in the previous section, the current body of literature on supply chain disruption strategies for commercial products by considering extraordinary risks such as epidemic or pandemic outbreaks is scarce. Therefore, it is crucial to develop a set of strategies by considering such extraordinary outbreaks for various types of products, especially for high-demand and essential items, as the smooth flow of these products is required for mass people to maintain their regular activities. Moreover, Paul and Chowdhury (2020) suggested that the same strategies might not be useful for all high-demand items. Hence, strategies need to be carefully selected by considering product characteristics and severity and duration of the impacts of an outbreak. This is where the main contribution of this study lies: the formulation and investigation of strategies for one of the high-demand and essential itemstoilet paper-during a pandemic outbreak. The study considered the product features in designing the strategies, which is not considered much in previous research. Besides, the majority of the supply chain disruption strategies are suggested for the post-disruption period. This study explores and analyzes the strategies that can be used during a pandemic situation to improve the service level of an essential product.

\section{Problem Description and Formulation}

During a pandemic, like COVID-19, it is common that there is a substantial level of panic buying, which increases the demand of certain items such as toilet papers, kitchen towels, and canned food (El-Terk 2020). On the other hand, manufacturers of those products face a significant decrease in their raw material supply, which creates this supplydemand problem in high tension. The ultimate result is that many customers, especially elders, will be in the empty hand of such essential items. In this critical situation, it is a social responsibility of manufacturers to ensure a higher level of production and distribution of these high-demand and essential items to serve more customers. To overcome this economic and operational challenge, this paper proposes some strategies to recover from these awkward situations and to improve the customer service level.
Firstly, we consider several local manufactures to produce the same item, such as toilet paper. In an ideal situation (no risk), they make their decision individually and serve the market. Then, we analyze the current practices during a pandemic situation. Currently, we observe that manufacturers still produce individually, but they use emergency sourcing, extra shifts, and purchase limit per customer to cover the higher demand. In the last, we have proposed some strategies and analyze results to recover from this pandemic situation.

\section{Ideal Plan}

In the ideal plan, there is no risk or disruption in the system. The demand, supply, and production capacities of a manufacturer are known. In this ideal situation, manufacturers make the products and deliver to the market based on their individual demand, supply, and capacity data. To determine the service of the ideal plan, we consider the following notations.

$M$ is the total number of manufacturers ( $m=1$ to $M$ )

$P$ is the total possible packet sizes $(p=1$ to $P$ )

$Q$ is the total number of possible quality options $(q=1$ to $Q$ )

$d_{q p m}$ is the demand of the product for manufacturer $m$ for packet size $p$ and quality option $q$.

Available raw materials are $r \%$ of the ideal demand. In the case of an ideal plan, we assume that $r$ is equal to 100 .

In the ideal plan, total quantity produced by all manufactures is determined as follows. Total quantity produced $=\sum_{q=1}^{Q} \sum_{p=1}^{P} \sum_{m=1}^{M} d_{q p m} \times \frac{r}{100}$

We determine the service level, as shown in Eq. (1).

$\begin{aligned} \text { Service level for the ideal plan }= & \frac{\sum_{q=1}^{Q} \sum_{p=1}^{P} \sum_{m=1}^{M} d_{q p m}}{\sum_{q=1}^{Q} \sum_{p=1}^{P} \sum_{m=1}^{M} d_{q p m}} \\ & \times \frac{r}{100}\end{aligned}$

\section{Current Practices}

Currently, there are shortages of raw materials of toilet papers. As the first step, companies have used the buffer materials kept for disruption management (Hudecheck et al. 2020). Currently, all companies individually employ their backup and alternative suppliers to increase sourcing quantity (Linton and Vakil 2020). Previous outbreaks, such as March 2011 Tsunami in Fukushima, Japan and 2014 Ebola in West Africa, educated the companies to keep alternative and multiple suppliers in various regions to be able to source from other regions when the affected region cannot provide required materials (Aldrighetti et al. 2019; 
Linton and Vakil 2020). This spreading of suppliers includes the suppliers in different tiers. Companies that had already mapped their supply base in early 2020 after the outbreak already knew that even if they do not source the materials from the most affected areas of COVID-19, maybe their suppliers do. Hence, firms have been utilizing the lessons of supply chain mapping in making potential strategies to increase the volume of sourced materials. Moreover, companies are maintaining regular communication with their suppliers to understand their contingency plan to deliver additional materials.

Companies have also increased the number of shifts to ensure that they are optimally utilizing their production capabilities to fulfill the shortage. For example, KimberlyClark, the largest Australian toilet paper manufacturer, has moved to $24 \mathrm{~h}$ of production to increase the supply of toilet paper (Bagshaw and Powell 2020). In the process of running more shifts, many manufacturers have recruited more staff to ensure that they can run the production facility $24 \mathrm{~h}$ a day. Currently, manufacturers make the decision themselves, and they produce different varieties of quality products such as single-, two-, and three-ply. Moreover, at present, packet sizes are different such as 4 rolls, 12 rolls, 24 rolls, and 48 rolls. Finally, there is a purchase limit, such as one customer can buy only one pack of toilet paper per customer in the retail store, for example.

We assume that demand increases could be certain times of the current demand, such as 2 times and 3 times. There is a shortage of raw materials. Emergency sourcing is possible up to a certain level, such as $0-100 \%$ of the ideal demand. The objective is to serve more customers and improve the service level.

The increased demand $\left(D_{q p m}\right)$ of the item of quality $q$ and packet size $p$ from manufacturer $m$ is calculated as follows.

$D_{q p m}=N_{1} d_{q p m}$

Here, $N_{1}$ is the times of demand increased and greater than 1.

If one customer buys one pack, the total number of customers to be served is determined as follows.

Total number of customer to be served $=\sum_{q=1}^{Q} \sum_{p=1}^{P} \sum_{m=1}^{M} D_{q p m}$

Availability of raw material $=r \%$ of the ideal demand Emergency sourcing $=s \%$ of the ideal demand

Total quantity produced $=\sum_{q=1}^{Q} \sum_{p=1}^{P} \sum_{m=1}^{M} d_{q p m} \times \frac{r+s}{100}$

For the current practice, we determine the service level, as presented in Eq. (4).
Service level for the current practic

$$
=\frac{\sum_{q=1}^{Q} \sum_{p=1}^{P} \sum_{m=1}^{M} d_{q p m} \times \frac{r+s}{100}}{\sum_{q=1}^{Q} \sum_{p=1}^{P} \sum_{m=1}^{M} D_{q p m}} \times 100 \%
$$

\section{Proposed Strategies}

During a pandemic situation and for a high-demand and essential item like toilet paper, we propose the following strategies to increase the production quantity and to serve more customers, hence the service level. The main objective is to serve more customers and improve the service level.

The target number of customers to be served is calculated using Eq. (5).

$D=N_{2} \sum_{q=1}^{Q} \sum_{p=1}^{P} \sum_{m=1}^{M} D_{q p m}$

Here, $N_{2}$ is the times of demand increased due to basic quality and smaller packs and greater than 1 .

The study has considered and analyzed four main strategies to improve the service level. These strategies are discussed below:

Strategy 1 Resource sharing among all manufacturers.

This strategy is a part of flexible supply chains (Singh et al. 2019), in which all manufacturers in a country should collaborate, share resources, and produce a single brand of the item. While companies typically do not share their resources and information with the competitors to ensure a competitive edge and more market share and profit, they are required to do that during a pandemic for a high-demand and essential item, such as toilet paper, considering that meeting the increased demand of individuals and communities is a social responsibility of all the manufactures. Because of resource sharing, a manufacturer can supplement the inadequate raw materials of other manufacturers, which will increase the availability of raw materials to produce more products. Let us assume that three different raw materials are needed to produce a product. A manufacturer may have two of them, while another manufacturer may have other types of raw material. By sharing resources, both companies can produce a certain amount of more products. We argue that coordinating activities and response plans and sharing resources with competitors can be an effective strategy. Recently, in Australia, the Australian Competition and Consumer Commission (ACCC) has granted authorization to Banks, grocery retailers, and medical equipment suppliers to allow them to coordinate with the competitors (Claytonutz 2020). This strategy aligns with Koonin (2020), who reports that alliances with other businesses could potentially be used as a recovery plan from COVID-19. 
Strategy 2 Use of collective emergency sourcing.

In the second strategy, manufacturers in a country will collectively, rather than individually what companies are now doing, explore the options to increase the quantity of sourced materials. They together may go for sourcing from a new location from where it is not feasible for the individual manufacturer to source materials. They all also can utilize the backup and alternative suppliers of each other to increase collective emergency sourcing. This strategy is possible when all manufacturers collaborate, share their information, and work together to source materials, which are the segments of the flexible supply chains (Wadhwa et al. 2009). This horizontal sourcing approach is also discussed in Orsdemir et al. (2019).

Strategy 3 Produce basic quality items.

In the third strategy, we propose the manufacturers to offer basic quality items, rather than providing premium quality items, during a pandemic situation to increase the volume of production. For example, in the case of toilet paper, manufacturers will produce one-ply toilet rolls instead of two- or three-ply. This can potentially enable companies to serve more customers.

Strategy 4 Pack the product with a minimum standard size.

It this strategy, manufacturers will pack the items with a minimum standard size to increase the total number of packets and serve more customers. For example, in the case of toilet paper, manufacturers will produce a pack with four rolls instead of 12,24 , or 48 rolls.

Using the proposed above four strategies, the total quantity produced is calculated as follows.

Total quantity produced $=$

$\left(\sum_{q=1}^{Q} \sum_{p=1}^{P} \sum_{m=1}^{M} d_{q p m} \times\right.$ quality factor $\times$ packet size factor $)$

$\times \frac{r+s}{100}$

We determine the service level, as presented in Eq. (6).

Service level for the proposed strategies $=$

$\underline{\left(\sum_{q=1}^{Q} \sum_{p=1}^{P} \sum_{m=1}^{M}\left(d_{q p m} \times \text { quality factor } \times \text { packet size factor }\right)\right)}$

$\times \frac{r+s}{100} N_{2} \sum_{q=1}^{Q} \sum_{p=1}^{P} \sum_{m=1}^{M} D_{q p m}$

\section{Analyzing Results}

We use hypothetical data to explain the results for a highdemand and essential item during a pandemic. In this example, we consider toilet paper as an item. We analyze the results for an ideal situation, current practices during a pandemic, and proposed strategies for managing the impacts.

\section{Results of Ideal Plan}

In the ideal plan, we assume that there are three manufactures with the demand data, as presented in Table 1.

As we assume that there is no shortage of raw materials, we calculated the service level by using Eq. (1), which is $100 \%$.

\section{Results of Current Practices}

During the pandemic, we use the following additional data. $N_{1}=3 ; r=50 \% ; s=30 \%$

Customers can buy one pack of the item at a time.

Using Eq. (4), we calculate the service level is only $27 \%$. Service level falls significantly because of a shortage of raw materials, limited emergency sourcing, and significant demand increment. In the current practice, total customers can be served only 4904 out of expected customers 18,390 .

\section{Results of Proposed Strategies}

To overcome the shortage of supply and surge of demand during a pandemic, we use four strategies, as described in Sect. 3.3. We consider the following data.

A basic quality toilet paper has 1 ply. If we produce 1 ply toilet roll instead of 3 ply, the quality factor would be 3 . If we produce 1 ply toilet roll instead of 2 ply, the quality factor would be 2 .

Smallest pack size has 4 rolls per pack. If we produce 4 rolls in a packet instead of 12 rolls, packet size factor would be 3 . If we produce 4 rolls in a packet instead of 48 rolls, packet size factor would be 12 .

$r=60 \%$, we assume a $10 \%$ increase in raw material availability because of collaboration and resource sharing.

$s=35 \%$, we assume a $5 \%$ increase in emergency sourcing because of information sharing and sourcing collectively.

$N_{2}=5$

Target customer to be served is calculated using Eq. (5), which is 91,950 . Service level is improved to $86 \%$ [using the Eq. (6)]. This means total 78,897 customers can be served by implementing the prospered four strategies. 
Table 1 Demand data in the ideal plan

\begin{tabular}{llllll}
\hline $\begin{array}{l}\text { Manufacturer } \\
1\end{array}$ & $\begin{array}{l}\text { Demand } \\
\text { quantity }\end{array}$ & $\begin{array}{l}\text { Manufacturer } \\
\text { quantity }\end{array}$ & $\begin{array}{l}\text { Demufacturer } \\
\text { quand }\end{array}$ & $\begin{array}{l}\text { Demand } \\
\text { quantity }\end{array}$ \\
\hline$d_{111}$ & 100 & $d_{112}$ & 50 & $d_{113}$ & 60 \\
$d_{121}$ & 200 & $d_{122}$ & 50 & $d_{123}$ & 50 \\
$d_{131}$ & 200 & $d_{132}$ & 100 & $d_{133}$ & 100 \\
$d_{141}$ & 100 & $d_{142}$ & 200 & $d_{143}$ & 100 \\
$d_{211}$ & 300 & $d_{212}$ & 100 & $d_{213}$ & 120 \\
$d_{221}$ & 200 & $d_{222}$ & 150 & $d_{223}$ & 200 \\
$d_{231}$ & 100 & $d_{232}$ & 200 & $d_{233}$ & 150 \\
$d_{241}$ & 300 & $d_{242}$ & 200 & $d_{243}$ & 200 \\
$d_{311}$ & 300 & $d_{312}$ & 100 & $d_{313}$ & 300 \\
$d_{321}$ & 300 & $d_{322}$ & 200 & $d_{323}$ & 200 \\
$d_{331}$ & 300 & $d_{332}$ & 100 & $d_{333}$ & 100 \\
$d_{341}$ & 400 & $d_{342}$ & 200 & $d_{343}$ & 100 \\
\hline
\end{tabular}

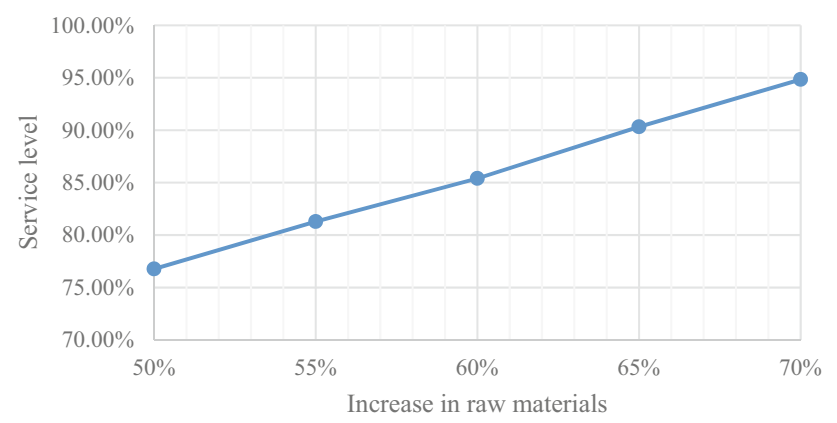

Fig. 1 Impact of resource sharing among all manufacturers on the service level

\section{Impact of Resource Sharing Among all Manufacturers}

We analyze the impact of resource sharing among all manufacturers on the service level, which is presented in Fig. 1. Resource sharing among all manufactures increases the available raw materials, and we have observed that the

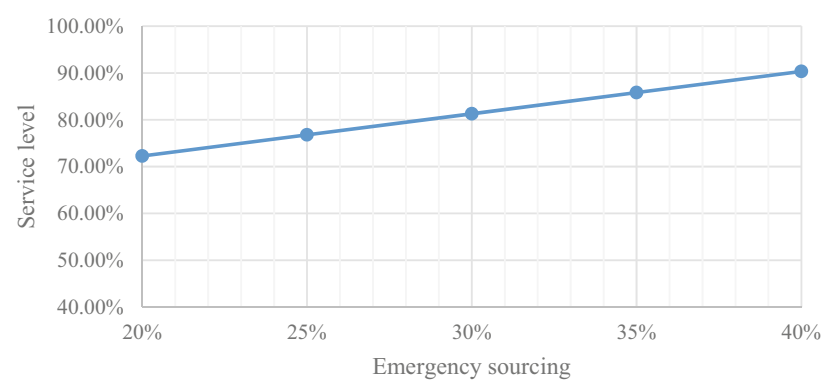

Fig. 2 Impact of collective emergency sourcing on the service level service level is increased with increasing the available raw materials.

\section{Impact of the Use of Collective Emergency Sourcing}

Collective emergency sourcing helps to increase the raw materials from emergency sources, which has a positive impact on the service level. Figure 2 shows that the service level improves with increasing the amount of emergency sourcing.

\section{Practical Implications}

The government, World Health Organization, and health care agencies are working hard to stop or reduce the spread of COVID-19; however, many manufacturing industries are struggling to absorb and manage the growing impact of this epidemic (Linton and Vakil 2020). This study shows, through an example of toilet papers, how manufacturers of high-demand items can increase the service level during a pandemic. While the study proposes and analyzed four strategies, manufactures may consider implementing all or one or multiple of the strategies to improve the service level. However, different strategies will have a different impact on improvement. When companies collaborate and share resources with competitors to increase the availability of raw materials, the production quantities and, ultimately, the service level are increased.

However, it would not be realistic to consider a significant increase in the availability of raw material as shortages may come from suppliers, and manufacturers may not have sufficient resources to share. As a result, companies can be better benefitted via implementing the second strategy, collective emergency sourcing, together with the first strategy. In such a situation, manufacturers not only get access to the resources of other manufacturers but also increase the amount of emergency sourcing. Hence, the production quantity will increase, which will help improve the service level. All manufacturers should share their information quickly to utilize all available emergency sources. However, in general, emergency sourcing is costly compared to standard sourcing. However, in the case of a pandemic, manufacturers should consider emergency sourcing to improve service level, hence serving more customers.

The study also suggests the manufactures of toilet papers producing basic quality items and the standard minimum packet size during a pandemic to improve the service level substantially. These strategies assist in improving the probability that the necessary items are more uniformly distributed, and more customers are served. Finally, the findings of the study suggest that the 
government and policymakers of a country should support the manufacturers to overcome this nation-wide shortage of supply. For example, to implement the first two strategies, manufacturers need authorization from the policymakers (Claytonutz 2020). While this study solves a current and real-world problem and has more managerial implications, the findings have also contributed to the literature by developing an analytical model to improve high-demand and essential items during a pandemic.

During an extraordinary crisis, like COVID-19, strategies under flexible manufacturing and supply chains play a significant role in recovering the impact (Altay et al. 2018; Hosseini et al. 2019; Qamar et al. 2019). For example, a positive and flexible mindset is vital for implementing the 'resource sharing among all manufacturers' and 'use of collective emergency sourcing' strategies. Under normal circumstances, generally, manufacturers do not collaborate with their competitors for resource sharing and collective emergency sourcing. However, considering the significant impact of the COVID-19 and limited application and usefulness of the traditional disruption management strategies (Ivanov 2020a), we suggest manufacturers be flexible in formulating policies at both strategic and operational levels.

The other two strategies, 'produce basic quality items' and 'pack the product with a minimum standard size,' are parts of flexible manufacturing. Generally, manufacturers are reluctant to produce only basic quality items and pack them with a minimum standard size, as these may affect their reputation and competitive advantage. However, during a severe crisis moment, like COVID-19, it is recommended that manufacturers produce essential items through close collaboration with each other to serve more customers by maintaining basic quality and minimum standard pack size. Such flexible strategies, on the one hand, improve service level and, on the other hand, protect the reputation or competitive advantages of a particular manufacturer.

\section{Conclusions}

It is a social responsibility of manufactures to produce and distribute highly demand items such as toilet paper during a crisis time such as COVID-19. In this research, we have suggested several strategies to recover during a pandemic situation for this high-demand and essential item. Overall, as shown in this study, it is suggested that the manufacturers work together to share resources and source jointly in the emergency and focus more on basic quality and size, rather than focusing on premium quality, to serve more customers. The results show that the proposed strategies help to improve the service level of the high-demand and essential items during a pandemic outbreak, such as COVID-19.

While the study has substantial implications for economic and operational practices, the study also has several limitations. First, the analytical model is only applicable to a high-demand and essential item to improve the service level. Second, one or more of the strategies may not be applicable to other high-demand and essential items. For example, by producing lower ply items, it is possible to produce more quantity, which may not be applicable to other products such as hand sanitizer. Third, this study used hypothetical data to analyze the model. In the future, this study can be extended to develop a decision-making and optimization model considering both demand and supply disruptions in a pandemic situation. This study can be further extended to developing decision-making models in global and complex supply chain systems. In addition, comprehensive empirical research using in-depth case studies or a large-scale survey could be undertaken to develop a theory regarding supply chain recovery plans and strategies for high-demand and essential items during an extraordinary outbreak such as COVID-19 (Pal and Altay 2019).

\section{References}

Aldrighetti, R., Zennaro, I., Finco, S., \& Battini, D. (2019). Healthcare supply chain simulation with disruption considerations: a case study from Northern Italy. Global Journal of Flexible Systems Management, 20, 81-102. https://doi.org/ 10.1007/s40171-019-00223-8.

Al Masud, M. A., Paul, S. K., \& Azeem, A. (2014). Optimisation of a production inventory model with reliability considerations. International Journal of Logistics Systems and Management, 17(1), 22-45. https://doi.org/10.1504/IJLSM.2014.057979.

Altay, N., Gunasekaran, A., Dubey, R., \& Childe, S. J. (2018). Agility and resilience as antecedents of supply chain performance under moderating effects of organizational culture within the humanitarian setting: A dynamic capability view. Production Planning and Control, 29(14), 1158-1174. https://doi.org/10.1080/ 09537287.2018 .1542174$.

Altay, N., \& Pal, R. (2014). Information diffusion among agents: Implications for humanitarian operations. Production and Operations Management, 23(6), 1015-1027. https://doi.org/10.1111/ poms. 12102.

Aslam, H., Blome, C., Roscoe, S., \& Azhar, T. M. (2018). Dynamic supply chain capabilities: How market sensing, supply chain agility and adaptability affect supply chain ambidexterity. International Journal of Operations and Production Management, 38(12), 226-2285.

Bagshaw, E., \& Powell, D. (2020). 'Supermarkets stockpile, toilet paper production runs 24 hours. The Sydney Morning Herald, Published on 03 March, 2020.

Cappelli, A., \& Cini, E. (2020). Will the COVID-19 pandemic make us reconsider the relevance of short food supply chains and local productions? Trends in Food Science \& Technology, 99, 566-567. https://doi.org/10.1016/j.tifs.2020.03.041. 
Chang, H. H., Wong, K. H., \& Chiu, W. S. (2019). The effects of business systems leveraging on supply chain performance: Process innovation and uncertainty as moderators. Information \& Management. https://doi.org/10.1016/j.im.2019.01.002.

Chen, H. Y., Das, A., \& Ivanov, D. (2019). Building resilience and managing post-disruption supply chain recovery: Lessons from the information and communication technology industry. International Journal of Information Management, 49, 330-342. https://doi.org/10.1016/j.ijinfomgt.2019.06.002.

Chen, J., Sohal, A. S., \& Prajogo, D. I. (2013). Supply chain operational risk mitigation: A collaborative approach. International Journal of Production Research, 51(7), 2186-2199.

Choi, T. (2020). Innovative "bring-service-near-your-home" operations under Corona-virus (COVID-19/SARS-CoV-2) outbreak: Can logistics become the messiah? Transportation Research Part E: Logistics and Transportation Review. https://doi.org/10. 1016/j.tre.2020.101961. (in press).

Chowdhury, P., Lau, K. H., \& Pittayachawan, S. (2016). 'Supply risk mitigation of small and medium enterprises: a social capital approach'. In The Proceedings of 21st International Symposium on Logistics. Centre for Concurrent Enterprise, Nottingham University, pp. 37-44.

Chowdhury, P., Lau, K. H., \& Pittayachawan, S. (2019). Operational supply risk mitigation of SME and its impact on operational performance: A social capital perspective. International Journal of Operations \& Production Management, 39(4), 478-502.

Chowdhury, P., \& Paul, S. K. (2020). Applications of MCDM methods in research on corporate sustainability: A systematic literature review. Management of Environmental Quality: An International Journal, 31(2), 385-405. https://doi.org/10.1108/ MEQ-12-2019-0284.

Claytonutz. (2020). COVID-19 response-competition and consumer law. Retrieved April 30, 2020, from https://www.claytonutz. com/covid-19-response/competition-and-consumer-law.

Darom, N. A., Hishamuddin, H., Ramli, R., \& Nopiah, Z. M. (2018). An inventory model of supply chain disruption recovery with safety stock and carbon emission consideration. Journal of Cleaner Production, 197, 1011-1021. https://doi.org/10.10 16/j.jclepro.2018.06.246.

Dasaklis, T. K., Pappis, C. P., \& Rachaniotis, N. P. (2012). Epidemics control and logistics operations: A review. International Journal of Production Economics, 139(2), 393-410. https://doi.org/10.10 16/j.ijpe.2012.05.023.

Dryhurst, S., Schneider, C. R., Kerr, J., Freeman, A. L., Recchia, G., Van Der Bles, A. M., et al. (2020). Risk perceptions of COVID19 around the world. Journal of Risk Research. https://doi.org/ 10.1080/13669877.2020.1758193. (in press).

Dubey, R., Altay, N., Gunasekaran, A., Blome, C., Papadopoulos, T., \& Childe, S. J. (2018). Supply chain agility, adaptability and alignment: Empirical evidence from the Indian auto components industry. International Journal of Operations and Production Management, 38(1), 129-148. https://doi.org/10.1108/IJOP M-04-2016-0173.

Dubey, R., \& Gunasekaran, A. (2016). The sustainable humanitarian supply chain design: Agility, adaptability and alignment. International Journal of Logistics Research and Applications, 19(1), 62-82. https://doi.org/10.1080/13675567.2015.1015511.

Dubey, R., Gunasekaran, A., \& Childe, S. J. (2015). The design of a responsive sustainable supply chain network under uncertainty. International Journal of Advanced Manufacturing Technology, 80(1-4), 427-445. https://doi.org/10.1007/s00170-015-6967-8.

DuHadway, S., Carnovale, S., \& Hazen, B. (2019). Understanding risk management for intentional supply chain disruptions: Risk detection, risk mitigation, and risk recovery. Annals of Operations Research.. https://doi.org/10.1007/s10479-017-2452-0. (in press).
El-Terk, N. (2020). 'Toilet paper, canned food: What explains coronavirus panic buying', Aljazeera. Retrieved May 26, 2020, from https://www.aljazeera.com/news/2020/03/toilet-paper-can ned-food-explains-coronavirus-panic-buying200313083341035.html.

Fartaj, S. R., Kabir, G., Eghujovbo, V., Ali, S. M., \& Paul, S. K. (2020). Modeling transportation disruptions in the supply chain of automotive parts manufacturing company. International Journal of Production Economics, 222, 107511.

Gligor, D., Gligor, N., Holcomb, M., \& Bozkurt, S. (2019). Distinguishing between the concepts of supply chain agility and resilience: A multidisciplinary literature review. International Journal of Logistics Management, 30(2), 467-487. https://doi.org/10.1108/IJLM-10-2017-0259.

Govindan, K., Kannan, D., \& Shankar, K. M. (2014). Evaluating the drivers of corporate social responsibility in the mining industry with multi-criteria approach: A multi-stakeholder perspective. Journal of Cleaner Production, 84(1), 214-232. https://doi.org/10.1016/j.jclepro.2013.12.065.

Gunasekaran, A., Dubey, R., \& Singh, S. P. (2016). Flexible sustainable supply chain network design: Current trends, opportunities and future. Global Journal of Flexible Systems Management., 17(2), 109-112. https://doi.org/10.1007/s40171-01 6-0131-7.

Haren, P., \& Simchi-Levi, D. (2020). 'How Coronavirus could impact the global supply chain by mid-March'. Harvard Business Review. Retrieved May 13, 2020, from https://hbr.org/2020/ 02/how-coronavirus-could-impact-the-global-supply-chain-bymid-march.

Hills, G. (2020). COVID-19 and corporate purpose-four ways businesses can respond now. Retrieved May 24, 2020, from https://www.fsg.org/blog/covid-19-and-corporatepurpose $\%$ E2\%80\%94four-ways-businesses-can-respond-now.

Hosseini, S., Ivanov, D., \& Dolgui, A. (2019). Review of quantitative methods for supply chain resilience analysis. Transportation Research Part E: Logistics and Transportation Review., 125, 285-307. https://doi.org/10.1016/j.tre.2019.03.001.

Hudecheck, M., Sirén, C., Grichnik, D., \& Wincent, J. (2020). 'How companies can respond to the coronavirus'. MIT Sloan Management Review. Retrieved May 31, 2020, from https://sloanreview.mit.edu/article/how-companies-can-respondto-the-coronavirus/.

Islam, M. T., Azeem, A., Jabir, M., Paul, A., \& Paul, S. K. (2020). An inventory model for a three-stage supply chain with random capacities considering disruptions and supplier reliability. Annals of Operations Research. https://doi.org/10.1007/s10479-0 20-03639-z. (in press).

Ivanov, D. (2019). Disruption tails and revival policies: A simulation analysis of supply chain design and production-ordering systems in the recovery and post-disruption periods. Computers \& Industrial Engineering, 127, 558-570. https://doi.org/10.1016/ j.cie.2018.10.043.

Ivanov, D. (2020a). Predicting the impacts of epidemic outbreaks on global supply chains: A simulation-based analysis on the coronavirus outbreak (COVID-19/SARS-CoV-2) case. Transportation Research Part E: Logistics and Transportation Review, 136, 101922. https://doi.org/10.1016/j.tre.2020.101922.

Ivanov, D. (2020b). Viable supply chain model: integrating agility, resilience and sustainability perspectives. Lessons from and thinking beyond the COVID-19 pandemic. Annals of Operations Research. https://doi.org/10.1007/s10479-020-03640-6. (in press).

Ivanov, D., \& Dolgui, A. (2020). Viability of intertwined supply networks: Extending the supply chain resilience angles towards survivability. A position paper motivated by COVID-19 outbreak. International Journal of Production Research. https://doi.org/10.1080/00207543.2020.1750727. (in press). 
Ivanov, D., Dolgui, A., Sokolov, B., \& Ivanova, M. (2017). Literature review on disruption recovery in the supply chain. International Journal of Production Research, 55(20), 6158-6174. https://doi.org/10.1080/00207543.2017.1330572.

Ivanov, D., Pavlov, A., Dolgui, A., Pavlov, D., \& Sokolov, B. (2016). Disruption-driven supply chain (re)-planning and performance impact assessment with consideration of pro-active and recovery policies. Transportation Research Part E: Logistics and Transportation Review, 90, 7-24.

Ivanov, D., \& Sokolov, B. (2019). Simultaneous structural-operational control of supply chain dynamics and resilience. Annals of Operations Research, 283, 1191-1210. https://doi.org/10.100 7/s10479-019-03231-0.

Kahiluoto, H., Mäkinen, H., \& Kaseva, J. (2020). Supplying resilience through assessing diversity of responses to disruption. International Journal of Operations and Production Management. https://doi.org/10.1108/ijopm-01-2019-0006. (in press).

Koonin, L. M. (2020). Novel coronavirus disease (COVID-19) outbreak: Now is the time to refresh pandemic plans. Journal of Business Continuity \& Emergency Planning, 13(4), 1-15.

Kumar, P. S., \& Anbanandam, R. (2020). Theory building on supply chain resilience: a SAP-LAP analysis. Global Journal of Flexible Systems Management, 21(2), 113-133. https://doi.org/ 10.1007/s40171-020-00233-x.

Linton, T., \& Vakil, B. (2020). 'Coronavirus is proving we need more resilient supply chains'. Harvard Business Review. Harvard Business Review. Retrieved May 13, 2020, from https://hbr.org/2020/03/coronavirus-is-proving-that-we-needmore-resilient-supply-chains.

Lücker, F., Seifert, R. W., \& Biçer, I. (2019). Roles of inventory and reserve capacity in mitigating supply chain disruption risk. International Journal of Production Research, 57(4), 1238-1249. https://doi.org/10.1080/00207543.2018.1504173.

Oloruntoba, R., \& Gray, R. (2006). Humanitarian aid: An agile supply chain? Supply Chain Management: An International Journal, 11(2), 115-120. https://doi.org/10.1108/13598540610652492.

Orsdemir, A., Hu, B., \& Deshpande, V. (2019). Ensuring corporate social and environmental responsibility through vertical integration and horizontal sourcing. Manufacturing and Service Operations Management, 21(2), 417-434. https://doi.org/ 10.1287/msom.2018.0744.

Pal, R., \& Altay, N. (2019). Identifying key success factors for social enterprises serving base-of-pyramid markets through analysis of value chain complexities. Journal of Business Logistics, 40(2), 161-179. https://doi.org/10.1111/jbl.12212.

Paul, S. K., Asian, S., Goh, M., \& Torabi, S. A. (2019a). Managing sudden transportation disruptions in supply chains under delivery delay and quantity loss. Annals of Operations Research, 273(1-2), 783-814. https://doi.org/10.1007/s10479-017-2684-z.

Paul, S. K., Azeem, A., Sarker, R., \& Essam, D. (2014a). Development of a production inventory model with uncertainty and reliability considerations. Optimization and Engineering, 15(3), 697-720. https://doi.org/10.1007/s11081-013-9218-6.

Paul, S. K., \& Chowdhury, P. (2020). A production recovery plan in manufacturing supply chains for a high-demand item during COVID-19. International Journal of Physical Distribution \& Logistics

Management. https://doi.org/10.1108/ijpdlm-04-2020-0127. (in press).

Paul, S. K., \& Rahman, S. (2018). A quantitative and simulation model for managing sudden supply delay with fuzzy demand and safety stock. International Journal of Production Research, 56(13), 4377-4395. https://doi.org/10.1080/00207543.20 17.1412528.

Paul, S. K., Sarker, R., \& Essam, D. (2013). A disruption recovery model in a production-inventory system with demand uncertainty and process reliability. Lecture Notes in Computer
Science, 8104, 511-522. https://doi.org/10.1007/978-3-6 42-40925-7_47.

Paul, S. K., Sarker, R., \& Essam, D. (2014b). Real time disruption management for a two-stage batch production-inventory system with reliability considerations. European Journal of Operational Research, 237(1), 113-128. https://doi.org/10.1016/j.ejor.20 14.02.005.

Paul, S. K., Sarker, R., \& Essam, D. (2014c). Managing real-time demand fluctuation under a supplier-retailer coordinated system. International Journal of Production Economics, 158, 231-243. https://doi.org/10.1016/j.ijpe.2014.08.007.

Paul, S. K., Sarker, R., \& Essam, D. (2015a). A disruption recovery plan in a three-stage production-inventory system. Computers \& Operations Research, 57, 60-72. https://doi.org/10.1016/j.c or.2014.12.003.

Paul, S. K., Sarker, R., \& Essam, D. (2015b). Managing disruption in an imperfect production-inventory system. Computers \& Industrial Engineering, 84, 101-112. https://doi.org/10.101 6/j.cie.2014.09.013.

Paul, S. K., Sarker, R., \& Essam, D. (2016). Managing risk and disruption in production-inventory and supply chain systems: A review. Journal of Industrial and Management Optimization, 12(3), 1009-1029. https://doi.org/10.3934/jimo.2016.12.1009.

Paul, S. K., Sarker, R., \& Essam, D. (2017). A quantitative model for disruption mitigation in a supply chain. European Journal of Operational Research, 257(3), 881-895. https://doi.org/10.1016/j.ejor.2016.08.035.

Paul, S. K., Sarker, R., \& Essam, D. (2018). A reactive mitigation approach for managing supply disruption in a three-tier supply chain. Journal of Intelligent Manufacturing, 29(7), 1581-1597. https://doi.org/10.1007/s10845-016-1200-7.

Paul, S. K., Sarker, R., Essam, D., \& Lee, P. T. W. (2019b). A mathematical modelling approach for managing sudden disturbances in a three-tier manufacturing supply chain. Annals of Operations Research, 280(1-2), 299-335. https://doi.org/10.10 07/s10479-019-03251-w.

Pérez-Pérez, M., Kocabasoglu-Hillmer, C., Serrano-Bedia, A. M., \& López-Fernández, M. C. (2019). Manufacturing and Supply Chain Flexibility: Building an Integrative Conceptual Model Through Systematic Literature Review and Bibliometric Analysis. Global Journal of Flexible Systems Management, 20(Suppl 1), S1-S23.

Qamar, A., Hall, M. A., Chicksand, D., \& Collinson, S. (2019). Quality and flexibility performance trade-offs between lean and agile manufacturing firms in the automotive industry. Production Planning and Control. https://doi.org/10.1080/09537287.2 019.1681534. (in press).

Ray, P., \& Jenamani, M. (2016). Sourcing decision under disruption risk with supply and demand uncertainty: A newsvendor approach. Annals of Operations Research, 137(1), 237-262.

Roscoe, S., Eckstein, D., Blome, C., \& Goellner, M. (2020). Determining how internal and external process connectivity affect supply chain agility: A life-cycle theory perspective. Production Planning and Control., 31(1), 78-91. https://doi.org/10.1080/09537287.2019.1629704.

Saha, A. K., Paul, A., Azeem, A., \& Paul, S. K. (2020). Mitigating partial-disruption risk: A joint facility location and inventory model considering customers' preferences and the role of substitute products and backorder offers. Computers \& Operations Research, 117, 104884.

Salem, M., Van Quaquebeke, N., Besiou, M., \& Meyer, L. (2019). Intergroup leadership: How leaders can enhance performance of humanitarian operations. Production and Operations Management, 28(11), 2877-2897. https://doi.org/10.1111/poms.13085.

Scholten, K., Scott, P. S., \& Fynes, B. (2014). Mitigation processesantecedents for building supply chain resilience. Supply Chain 
Management: An International Journal, 19(2), 211-228. https://doi.org/10.1108/SCM-06-2013-0191.

Shao, X.-F., \& Dong, M. (2012). Supply disruption and reactive strategies in an assemble-to-order supply chain with timesensitive demand. IEEE Transactions on Engineering Management, 59(2), 201-212.

Singh, R. K., \& Acharya, P. (2013). Supply chain flexibility: A frame work of research dimensions. Global Journal of Flexible Systems Management, 14(3), 157-166.

Singh, R. K., Modgil, S., \& Acharya, P. (2019). Assessment of supply chain flexibility using system dynamics modeling. Global Journal of Flexible Systems Management, 20(1), 39-63.

Wadhwa, S., Madaan, J., \& Verma, M. (2009). Flexibility focused decision and information sharing model for product recovery system. Global Journal of Flexible Systems Management., 10(3), $15-22$.

Wamba, S. F., Dubey, R., Gunasekaran, A., \& Akter, S. (2020). The performance effects of big data analytics and supply chain ambidexterity: The moderating effect of environmental dynamism. International Journal of Production Economics, 222, 107498. https://doi.org/10.1016/j.ijpe.2019.09.019.

Worldometers (2020) COVID-19 Coronavirus Pandemic. Retrieved June 25, 2020, from https://www.worldometers.info/coronavirus/.

Yadav, D. K., \& Barve, A. (2016). Modeling post-disaster challenges of humanitarian supply chains: A TISM approach. Global Journal of Flexible Systems Management, 17(3), 321-340.

Zhao, K., Zuo, Z., \& Blackhurst, J. V. (2019). Modelling supply chain adaptation for disruptions: An empirically grounded complex adaptive systems approach. Journal of Operations Management., 65(2), 190-212. https://doi.org/10.1002/joom.1009.

Publisher's Note Springer Nature remains neutral with regard to jurisdictional claims in published maps and institutional affiliations.

\section{Key Questions}

1. What are the strategies that can be used to manage the increased demand for an essential item during a pandemic like COVID-19?

2. How can managers evaluate the improvement in service level after implementing the strategies?

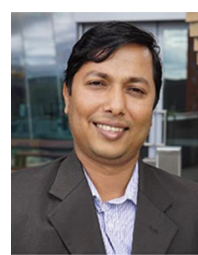

Dr Sanjoy Paul is currently working as a Senior Lecturer in operations and supply chain management at the University of Technology Sydney, Sydney, Australia. He has published more than 70 articles in top-tier journals and conferences including European Journal of Operational Research, International Journal of Production Economics, Computers and Operations Research, International Journal of Production Research, International Journal of Physical Distributions and Logistics Management, Annals of Operations Research, Journal of Management in Engineering, Journal of Cleaner Production, Computers and Industrial Engineering, Journal of Retailing and Consumer Services, and Journal of Intelligent Manufacturing. Dr Paul has received several awards in his career, including ASOR Rising Star Award (a national level award to recognize early career researchers in operations research), Excellence in Early Career Research Award from the UTS Business School, the Stephen Fester prize for most outstanding thesis, and high impact publications award for publishing articles in top-tier journals from the University of New South Wales (UNSW).

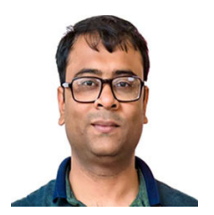

Dr Priyabrata Chowdhury is a Lecturer in Supply Chain Management at RMIT University, Melbourne, Australia. Dr Chowdhury obtained his $\mathrm{PhD}$ in Supply Chain Management and MBA in Marketing Studies and International Marketing. His research area includes supply chain risk and disruption management, supply chain resilience, supply chain sustainability, and strategic alliances in a supply chain. His research articles have appeared in the top-tier journals including International Journal of Operations and Production Management, International Journal of Physical Distributions and Logistics Management, Journal of Cleaner Production, and Benchmarking: An International Journal. 